\title{
Morphological Investigation of Nucleus Tractus Solitarius Somatotopy
}

\author{
Semih Keskil ${ }^{1}$, Engin Çalgüner ${ }^{2}$ and Rabet Gözil ${ }^{2}$ \\ ${ }^{1}$ Department of Neurosurgery, Fatih University Medical School, Emek, Ankara, Turkey and ${ }^{2}$ Department of Anatomy, \\ Gazi University School of Medicine, Beșevler, Ankara, Turkey
}

Received September 20, 2000; accepted March 7, 2001

\begin{abstract}
Taste is one of the most important senses that allows for human survival. Recent electrophysiological investigations have revealed some information about the somatotopy of the rat nucleus tractus solitarius (NTS). The aim of this study was to assess rat NTS somatotopy using morphological techniques.

Each animal was anesthetized and a retrograde axonal tracer, horseradish peroxidase, was injected intra- and submucosally into the anterior portion or the middle and posterior portions of the left half of rat tongue. After 24-48 hr, each rat was anesthetized again and perfusion-fixed. The brainstem was removed and cut in $50 \mu \mathrm{m}$-thick sections using a vibrotome. The sections were subjected to a tetramethylbenzidine-peroxidase

reaction, and were then assessed under light-microscopy.

The horseradish peroxidase that was deposited in the anterior third of the tongue labeled neuron cell bodies in the rostrofrontolateral region of the ipsilateral NTS, while that deposited in the middle and posterior thirds of the tongue labeled neuron cell bodies in the caudoposteromedial region of the ipsilateral NTS. There was no cross-projection.

The morphological findings were in accord with the electrophysiological results in the literature. Retrograde labeling revealed a distinct pattern of neural projection that corresponded to the anterior portion, and the middle and posterior portions of the tongue.
\end{abstract}

Key words: Taste, Nucleus tractus solitarius, Horseradish peroxidase, Somatotopy, Retrograde labeling

\section{Introduction}

Taste is one of the senses most vital to human survival. Afferent information from the oral cavity is conveyed by the chorda tympani branch of the facial nerve from the anterior two-thirds of the tongue; by the lingual branch of the glossopharyngeal nerve from the posterior third of the tongue; and by the internal branch of the superior laryngeal nerve (a branch of the vagus nerve) from the anterior surface of the epiglottis. All these pathways transmit sensory stimuli to the nucleus tractus solitarii of the brainstem [3, 14].

The entire tongue is sensitive to the four main taste qualities (sweet, sour, salty and bitter) but the tip of the tongue is more sensitive to sweet, the lateral borders to sour,

Data partly presented in the 4th National Congress of Anatomy, 1-5 September 1997, Kumburgaz, İstanbul.

Correspondence to: Dr. İ. Semih Keskil, Fethiye Sokak No: 4/6, Gazi Osman Paşa, 06700 Ankara, Turkey. the lateral areas of the anterior third to salty and the area near the sulcus terminalis to bitter $[3,14,18]$. The "specific pathways" theory suggests that a certain group of neurons carries the stimuli for a specific taste quality $[18,19]$. In contrast, the "interfibrillary coding" theory suggests that, although each fiber has a specific sensitivity for a given taste quality, each may also have lesser sensitivity to other taste qualities, and the central neurons analyze the impulses that are transmitted via many different fibrils [4]. Experiments have supported both theories; thus it is likely that mapping the patterns of projection for the taste stimuli in the central nervous system can only be done by comparing the electrophysiological activity in the quality-specific fibers to activity in other nonspecific fibrils $[4,5]$.

Recent electrophysiological investigations have shown that the somatotopic organisation of the nucleus tractus solitarius (NTS) for salty and bitter tastes corresponds to the map of these taste qualities on the tongue, but this has not yet been assessed morphologically [1, 10,11]. We undertook this study to assess whether the somatotopic organization of 

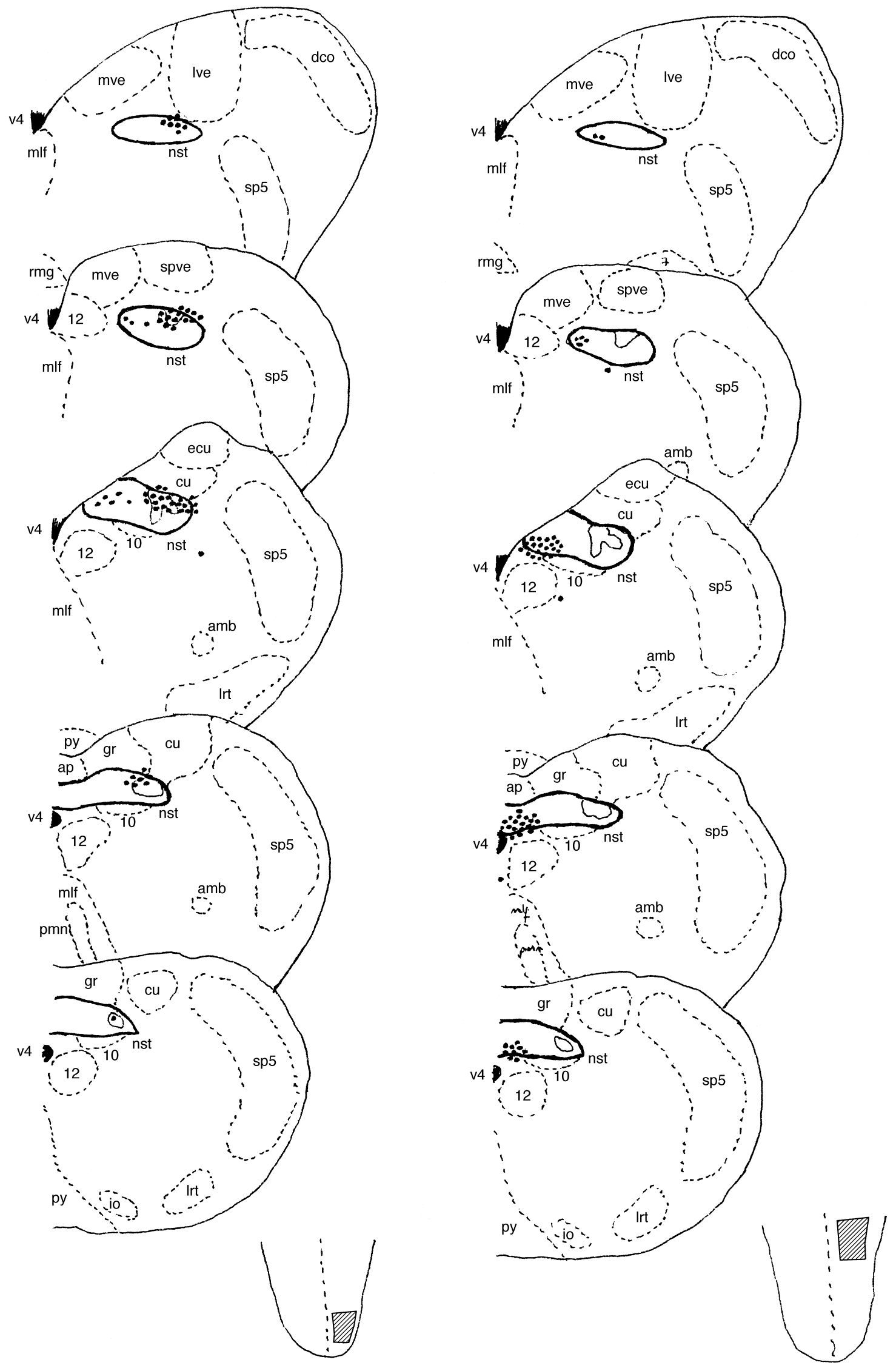

Fig. 1 


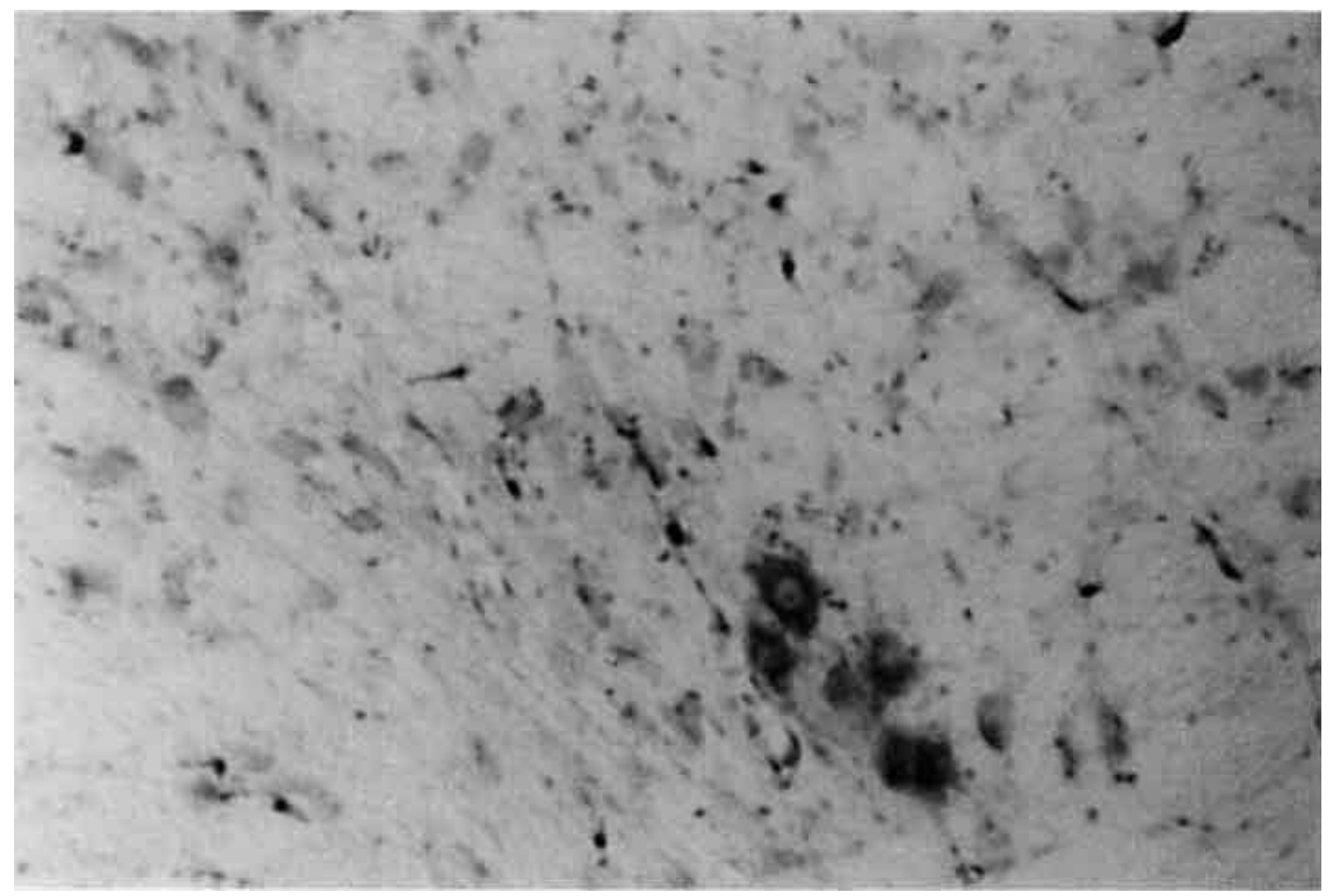

Fig. 2. The neuron cell bodies labeled by HRP injection into the anterior third of the tongue are located in the rostral region of the nucleus tractus solitarius on the brainstem section referred to as $5 \mathrm{~A}$ in Fig. 1. (neutral red, $\times 120$ ).

nerve cell bodies in the NTS corresponds to the distinct distribution of the taste quality projections to this brainstem nucleus.

\section{Materials and Methods}

Twelve male Wistar rats weighing 200-260 g were used in this study. The experiment was conducted with strict adherence to the Guide For the Care and Use of Laboratory Animals" (National Institutes of Health Publication No: 86$23)$. Each rat was anesthetized with an intraperitoneal injection of ketamine $(44 \mathrm{mg} / \mathrm{kg})$ and xylazine $(5 \mathrm{mg} / \mathrm{kg})$.

A total of $10 \mu \mathrm{l}$ of $30 \%$ horseradish peroxidase (HRP) (Sigma type 6) solution, a retrograde axonal tracer, were then slowly injected into the mucosa on the left side of each rat's tongue via glass micropipettes. In half of the animals $(n=6)$, we injected 10 different points in the anterior third of the tongue, and in the other half $(n=6)$ we injected 10 different points in the middle and posterior thirds of the tongue.

After $24 \mathrm{hr}$, the animals were reanesthetized and perfused with saline, followed by $1.25 \%$ glutaraldehyde and $1 \%$ paraformaldehyde in $0.1 \mathrm{M}$ phosphate buffer $(\mathrm{pH} 7.4)$. Postfixation times ranged from 1 to $2 \mathrm{hr}$.

We removed the brainstem en bloc and cut $50 \mu \mathrm{m}$-thick serial sections on a vibratome. Free floating sections were processed in the chromogen tetramethylbenzidine. To determine which neuronal cell bodies retrogradely labeled with intracytoplasmic HRP, we counterstained the sections with neutral red. Thus, neurons that did not contain HRP granules could also be morphologically assessed; and neurons that contained intracytoplasmic HRP reaction product could be compared to populations of unlabeled cells [12].

The counterstained brainstem sections were studied under light microscopy and camera lucida tracings were made. Intracellular HRP granules that were detected in the

Fig. 1. Camera lucida drawings of the brainstem sections obtained after HRP injection into the anterior third (left) or middle and posterior thirds (right) of the left half of the rat tongue. Sections are separated by intervals of $0.8 \mathrm{~mm}$ and are displayed in rostrocaudal order. The interrupted lines indicate the perimeters of various branistem nuclei, the continuous line outlines the nucleus tractus solitarius, and the dark dots represent neurons that contain intracellular granules of HRP reaction product.

Abbreviations: mlf, fasciculus longitudinalis medialis; mve, nuc. vestibularis medialis; lve, nuc. vestibularis lateralis; dco, nuc. cochlearis dorsalis; sp5, nuc. spinalis nervi trigeminalis; 7, nuc. nervi facialis; rmg, nuc. reticularis raphe magnus; spve, nuc. spinalis vestibularis; 12 , nuc. nervi hypoglossi; amb, nuc. ambiguus; cu, nuc. cuneatus; ecu, nuc. cuneatus externalis; 10, nuc. dorsalis nervi vagi; lrt, nuc. reticularis lateralis medulla oblongata; gr, nuc. gracilis; pmn, nuc. reticularis paramedianus; py, tractus pyramidalis; v4, ventriculus quartus; nst, nuc. tractus solitarius. 


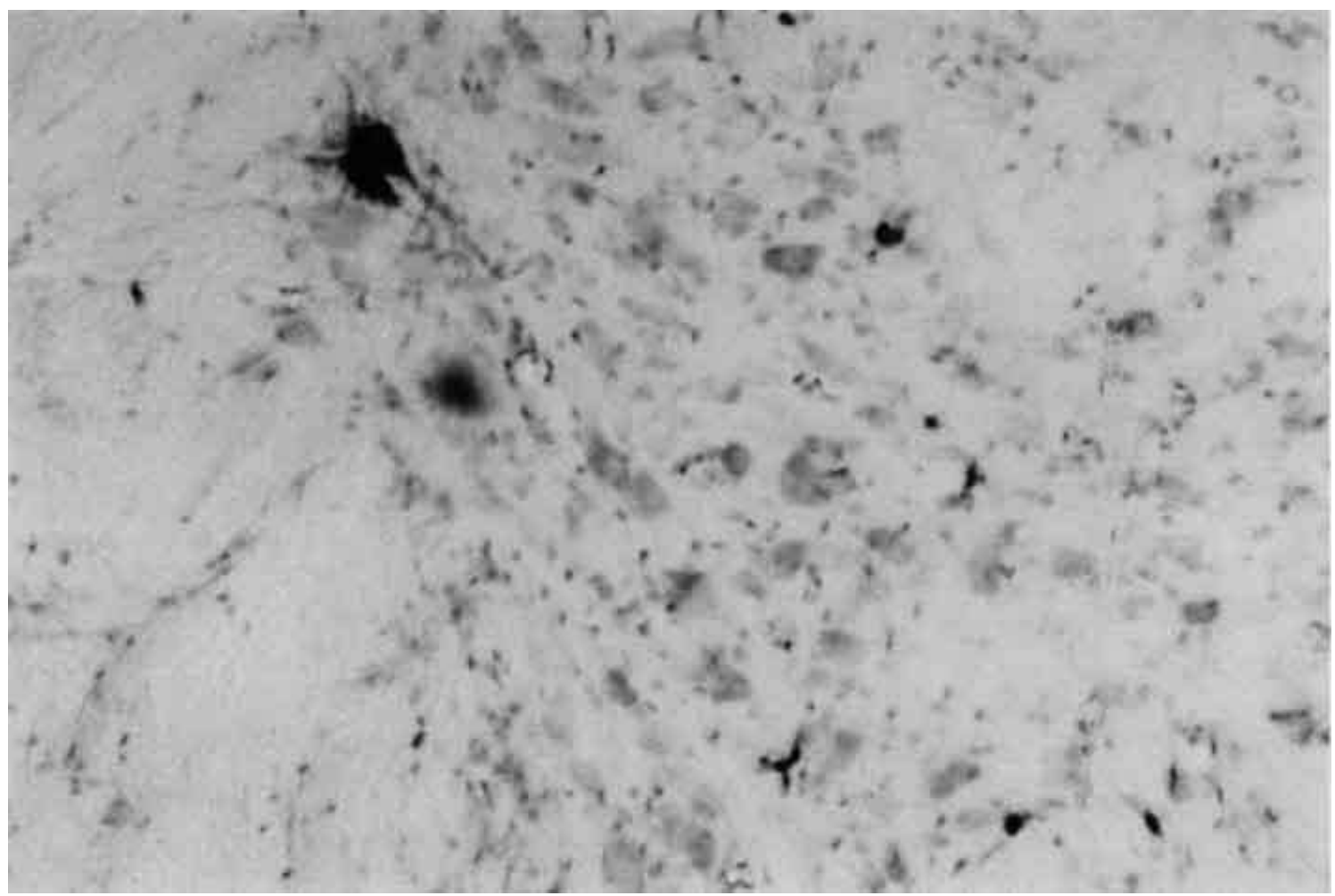

Fig. 3. The neuron cell bodies labeled by HRP injection into the middle and posterior thirds of the tongue are located in the nucleus tractus solitarius on the brainstem section referred to as $6 \mathrm{~A}$ in Fig. 1. (neutral red, $\times 120$ ).

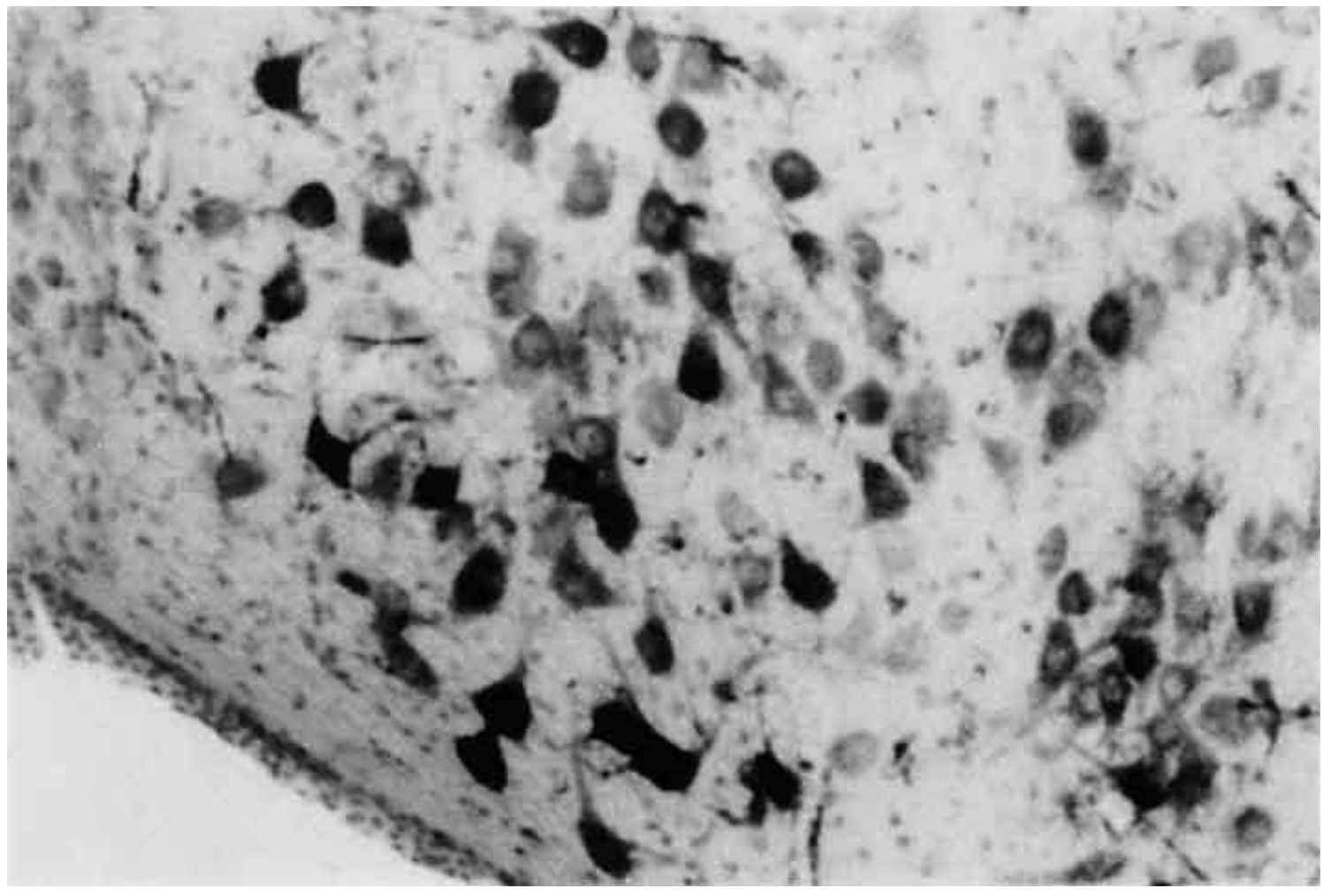

Fig. 4. Neuron cell bodies labeled by HRP injection into the anterior third of the tongue are located in the anterolateral region of the nucleus tractus solitarius on the brainstem section referred to as 5C in Fig. 1. (neutral red, $\times 120$ ). 


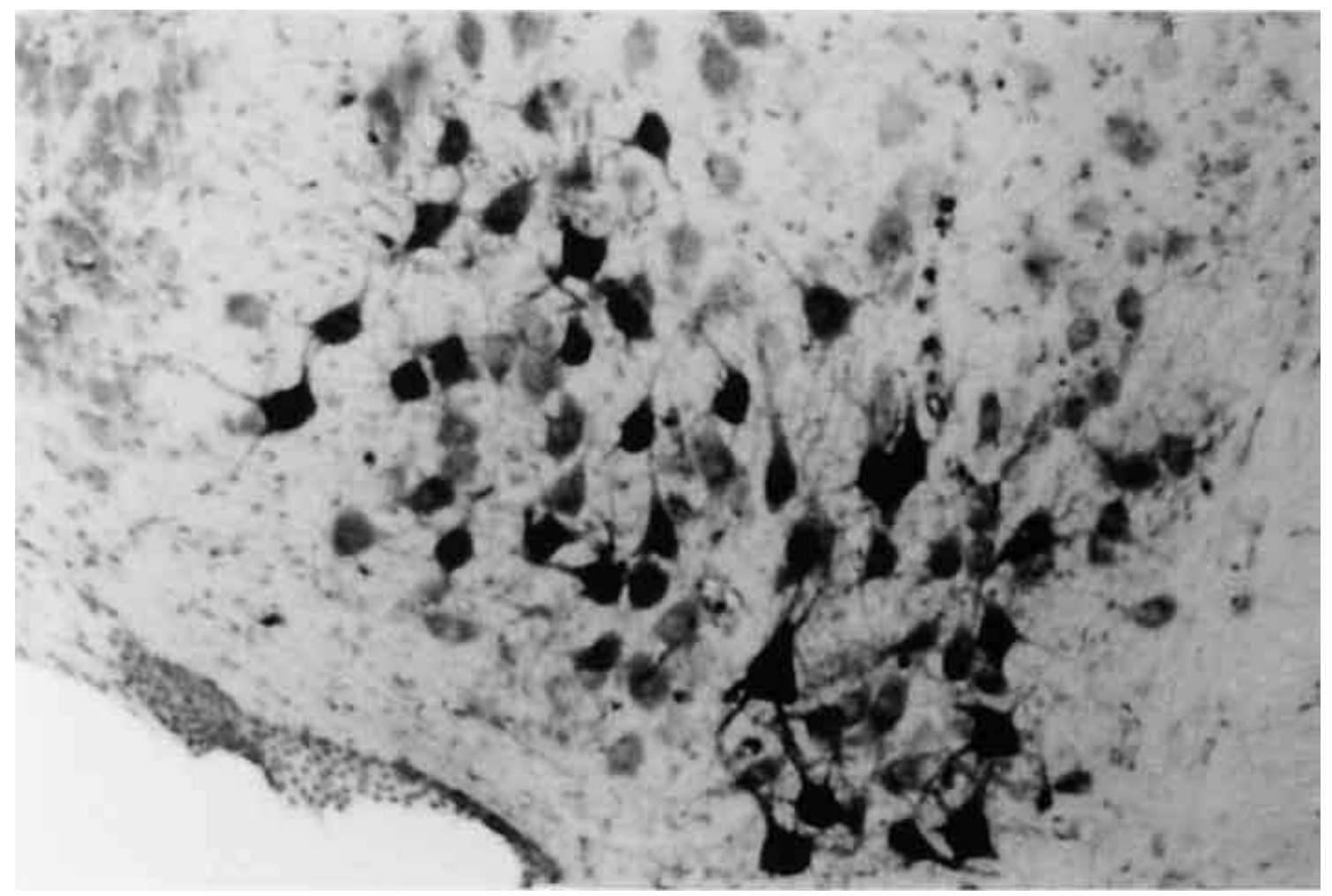

Fig. 5. Neuron cell bodies labeled by HRP injection into the middle and posterior thirds of the tongue are located in the posteromedial region of the nucleus tractus solitarius on the brainstem section referred to as 6C in Fig. 1. (neutral red, $\times 120$ ).

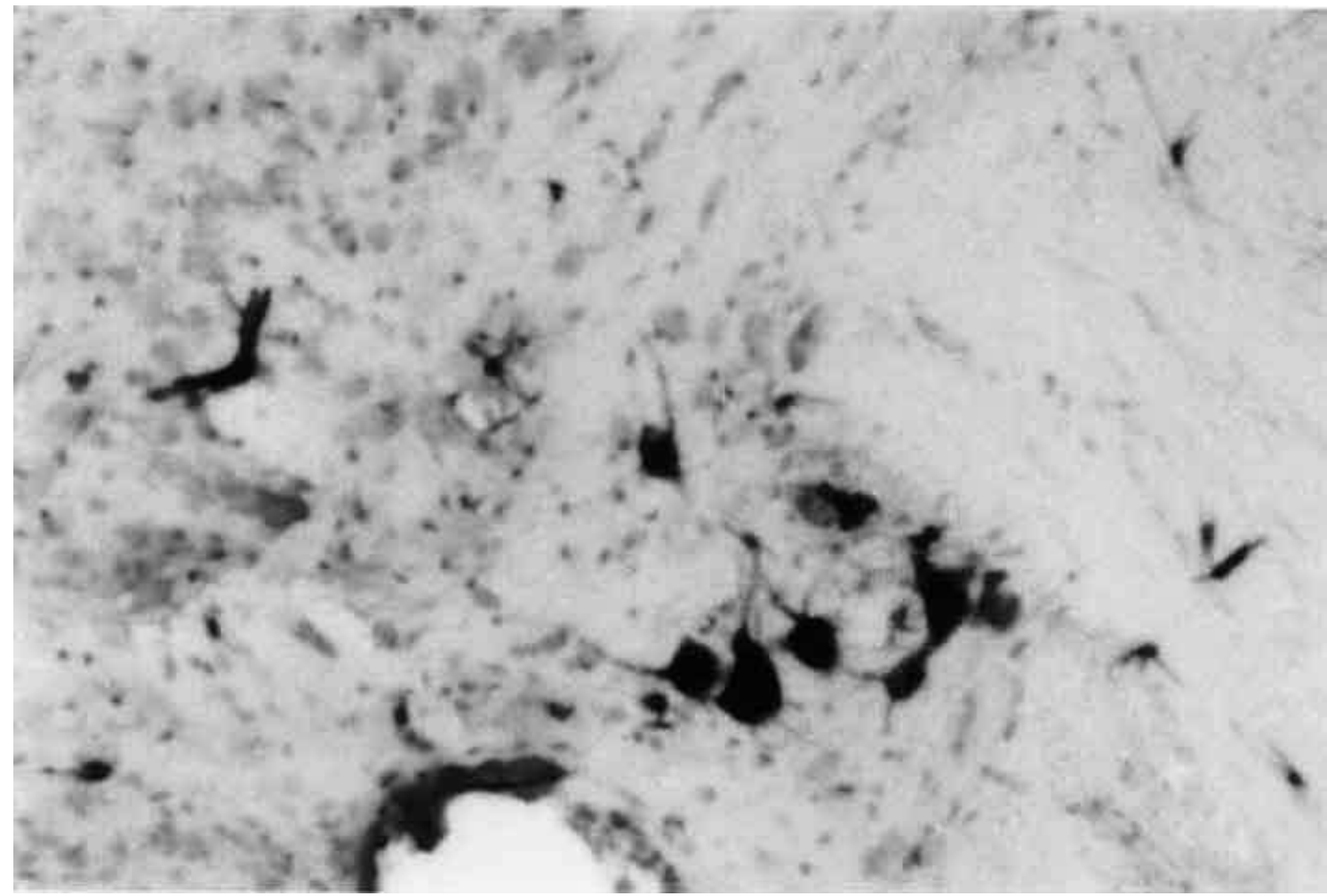

Fig. 6. Neuron cell bodies labeled by HRP injection into the anterior third of the tongue are situated in the caudal region of the nucleus tractus solitarius on the brainstem section referred to as $5 \mathrm{E}$ in Fig. 1. (neutral red, $\times 120$ ). 


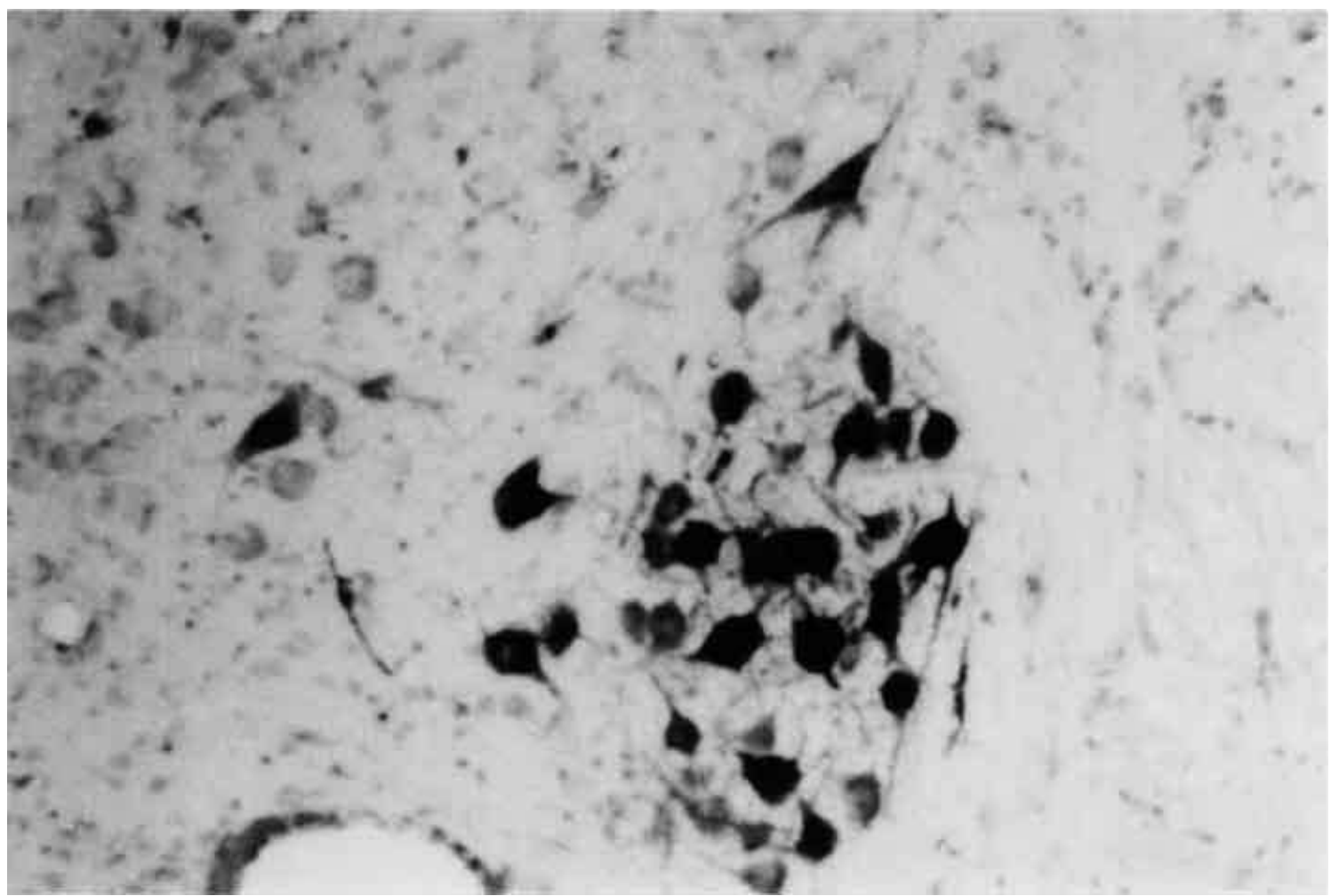

Fig. 7. Neuron cell bodies labeled by HRP injection into the middle and posterior thirds of the tongue are located in the caudal region of the nucleus tractus solitarius on the brainstem section referred to as $6 \mathrm{E}$ in Fig. 1. (neutral red, $\times 120$ ).

histological preparations were indicated by dark dots in these camera lucida drawings. The boundaries of the rat NTS were drawn according to widely accepted cytoarchitectonic criteria [9]. Finally, the brainstem section tracings were compared to photographs of normal tissue in a rat brain atlas [17]. Figure 1 shows a representative sample of the drawings presented in rostrocaudal sequence.

\section{Results}

HRP applied to the anterior third of the tongue labeled the rostral and anterolateral regions of the NTS, while HRP applied to the middle and posterior thirds of the tongue labeled the caudal and posteromedial regions of the ipsilateral nucleus (Fig. 1). There was no cross-projection.

Of the nerve cell bodies that were labeled by HRP, those located in the rostral regions of the nucleus (shown in the upper sections of Fig. 1) were mostly labeled by the tracer that was injected to the anterior third of the tongue (Figs. 2,3 ). However, cell bodies located in the middle regions of the nucleus on the rostrocaudal axis (shown in the middle sections of Fig. 1) were labeled by HRP that was injected into both the anterior and posterior parts of the tongue (Figs. 4,5 ). Neuron cell bodies located in the caudal regions of the nucleus on the rostrocaudal axis (shown in the lower sections of Fig. 1) were labeled by tracer that was injected into the middle and posterior thirds of the tongue (Figs. 6, 7).

\section{Discussion}

The first synapse of the gustatory system is within the taste bud. Since there are significantly more taste buds in the anterior part of the rat tongue than in other areas (two- to five times the numbers found in the posterior region) $[6,8,13]$, we chose to compare results of intramucosal HRP injection of the anterior third to results from injections into the middle and posterior thirds of the tongue. The receptive neuroepithelial cells in the taste bud form synapses with the afferent fibers $[23,26]$. Since these fibers also innervate the subepithelial tactile receptive bodies and epithelium surrounding the taste buds, they include somesthetic afferents from this region as well [16, 21, 22].

Hayama et al. [7] showed that most taste sense maps to the rostrocaudal regions of the NTS [7, 16, 21]. Electrophysiological studies have also shown that the NTS is topographically organized into regions that correspond to sweet, salty and bitter tastes similar to the tongue and thalamus $[1,2]$. Use of the term "orotopy", which refers to the topographic NTS representation of somatotopic sensibility in the tongue, has led to the adoption of the term "chemotopy" to describe the spatial patterning of the different chemosensitive receptor subgroups in the NTS $[4,5,10,15,20]$. Travers and colleagues [23-25] showed that taste-receiving nerve cell bodies in the rostral region of the rat NTS were located anterior and medial to the mechanically stimulated cells. Anteroposterior topography has also been demonstrated 
in the mapping of projections from the taste neurons, in that stimulation of the anterior tongue mostly activates cells in the anterorostral region of the NTS, whereas posterior tongue stimulation activates cells in the rostrolateral region [23-25]. In our study, HRP applied to the anterior third of the rat tongue labeled the anterolateral region of the NTS, and HRP applied to the middle and posterior thirds of the tongue labeled the posteromedial region.

In conclusion, our morphological findings support the orotopy that has been demonstrated in electrophysiological experiments. Neural pathways that started in the anterior third of the tongue projected to the rostrofrontolateral region of the NTS; and pathways from the middle and posterior thirds of the tongue projected to the caudoposteromedial region of the nucleus. It remains to be seen whether the pattern of somatotopic organization in the human NTS is similar to that in the rat. One possible investigative approach may be to assess taste perception and orotopy in patients with brainstem lesions.

\section{Acknowledgments}

The authors would like to thank Associate Professor Alper Atasever, MD from the Department of Anatomy at Hacettepe University School of Medicine, Sihhiye, Ankara for his technical help and valuable comments.

\section{References}

1. Dickman, J. D. and Smith, D. V.: Topographic distribution of taste responsiveness in the hamster medulla. Chem. Senses 14; 231-247, 1989.

2. Dodd, J. and Castellucci, V. F.: Smell and taste. In "Principles of Neural Sciences", ed. by E. R. Kandel, J. H. Schwartz and T. M. Jessell, 3rd ed., Elsevier, New York, 1991, pp. 512-529.

3. Drenckhahn, D. and Zenker, W.: Benninghoff Anatomie, Bd I, Urban-Schwarzenberg, München, 1994, pp. 807-811.

4. Frank, M.: An analysis of hamster afferent taste nerve response functions. J. Gen. Physiol. 61; 588-618, 1973.

5. Frank, M. E., Contreras, R. J. and Hettinger, T. P.: Nerve fibers sensitive to ionic taste stimuli in chorda tympani of the rat. $J$. Neurophysiol. 50; 941-960, 1983.

6. Ganchrow, J. R. and Ganchrow, D.: Long-term effects of gustatory neurectomy on fungiform papillae in the young rat. Anat. Rec. 225; 224-231, 1989.

7. Hayama, T., Ito, S. and Ogawa, H.: Responses of solitary tract nucleus neurons to taste and mechanical stimulations of the oral cavity in decerebrate rats. Exp. Brain Res. 60; 235-242, 1985.

8. Hosley, M. A., Hughes, S. E., Morton, L. L. and Oakley, B.: A sensitive period for the neural induction of taste buds. J. Neuro- sci. 7; 2075-2080, 1987.

9. van der Kooy, D., Koda, L. Y., Mc Ginty, J. F., Gerfen, C. R. and Bloom, F. E.: The organization of projections from the cortex, amygdala, and hypothalamus to the nucleus of the solitary tract in rat. J. Comp. Neurol. 224; 1-24, 1984.

10. McPheeter, M., Hettinger, T. P., Nuding, S. C., Savoy, L. D., Whitehead, M. C. and Frank, M. E.: Taste responsive neurons and their locations in the solitary nucleus of the hamster. Neuroscience 34; 745-758, 1990.

11. McRitchie, D. A. and Törk, I.: The internal organization of the human solitary nucleus. Brain Res. Bull. 31; 171-193, 1993.

12. Mesulam, M. M.: Tetramethylbenzidine for horseradish peroxidase neurohistochemistry. A non-carcinogenic blue reactionproduct with superior sensitivity for visualing neural afferents. $J$. Histochem. Cytochem. 26; 106-117, 1978.

13. Miller, I. J.: Taste bud distribution and regional responsiveness on the anterior tongue of the rat. Physiol. Behav. 16; 439-444, 1976.

14. Moore, K. L.: Clinically Oriented Anatomy, 3rd ed., WilliamsWilkins, Baltimore, 1992, pp. 745-746.

15. Nejad, M. S.: The neural activities of the greater superficial petrosal nerve of the rat in response to chemical stimulation of the palate. Chem. Senses 11; 283-293, 1986.

16. Ogawa, H. and Hayama, T.: Receptive fields of solitario-parabrachial relay neurons responsive to natural stimulation of the oral cavity in rats. Exp. Brain Res. 54; 359-366, 1984.

17. Paxinos, G. and Watson, C.: The Rat Brain in Stereotactic Coordinates. Academic Press, Sydney, 1982.

18. Rolls, E. T.: Information processing in the taste system of primates. J. Exp. Biol. 146; 141-164, 1989.

19. Schmale, H., Holtgrewe-Grez, H. and Christiansen, H.: Possible role for salivary gland protein in taste reception indicated by homology to lipophilic-ligand carrier proteins. Nature 343; 366369, 1990.

20. Shingai, T. and Beidler, L.: Response characteristics of three taste nerves in mice. Brain Res. 335; 245-249, 1985.

21. Sweazey, R. D. and Smith, D. V.: Convergence onto hamster medullary taste neurons. Brain Res. 408; 173-185, 1987.

22. Torvick, A.: Afferent connections to the sensory trigeminal nuclei, the nucleus of the solitary tract and adjacent structures. An experimental study in the rat. J. Comp. Neurol. 106; 51-141, 1956. (Cited in Dickman, 1989)

23. Travers, S. P. and Nicklas, K.: Taste bud distribution in the rat pharynx and larynx. Anat. Rec. 227; 373-379, 1990.

24. Travers, S. P. and Norgren, R.: Coding the sweet taste in the nucleus of the solitary tract: differential roles for anterior tongue and nasoincisor duct gustatory receptors in the rat. J. Neurophysiol. 65; 1372-1380, 1991.

25. Travers, S. P. and Norgren, R.: Organization of orosensory responses in the nucleus of the solitary of the rat. J. Neurophysiol. 73; 2144-2162, 1995.

26. Travers, S. P., Pfaffmann, C. and Norgren, R.: Convergence of lingual and palatal gustatory neural activity in the nucleus of the solitary tract. Brain Res. 365; 305-320, 1986. 